\title{
Percutaneous interventions in cardiology in Poland in the year 2014. Summary report of the Association of Cardiovascular Interventions of the Polish Cardiac Society AISN PTK
} \author{
Sławomir Dobrzycki ${ }^{5}$, Marek Grygier ${ }^{6}$, Tomasz Moszura7, Tomasz Pawłowski ${ }^{8}$, Dariusz Dudek² \\ ${ }^{1}$ Department of Interventional Cardiology, GCM Hospital, Katowice, Poland \\ ${ }^{2}$ Department of Interventional Cardiology, Jagiellonian University Medical College, Krakow, Poland \\ ${ }^{3} 2^{\text {nd }}$ Department of Cardiology, Jagiellonian University Medical College, Krakow, Poland \\ ${ }^{4}$ Institute of Cardiology, Warsaw-Anin, Poland \\ ${ }^{5}$ Department of Cardiology, Medical University of Bialystok, Bialystok, Poland \\ ${ }^{6}$ Department of Cardiology, Medical University of Poznan, Poznan, Poland \\ ${ }^{7}$ Department of Cardiology in Children, Medical University of Poznan, Poznan, Poland \\ ${ }^{8}$ Central Clinical Hospital of the Ministry of Interior, Warsaw, Poland
}

Andrzej Ochała ${ }^{1}$, Zbigniew Siudak ${ }^{2}$, Jacek Legutko ${ }^{3}$, Radosław Parma ${ }^{1}$, Zbigniew Chmielak ${ }^{4}$, Stanisław Bartuś ${ }^{3}$,

Postep Kardiol Inter 2015; 11, 3 (41): 177-181

DOI: $10.5114 /$ pwki.2015.54009

\begin{abstract}
Introduction: The Board of the Association of Cardiovascular Interventions of the Polish Cardiac Society (AISN PTK) publishes annual data from the National PCI Registry (ORPKI) operated by the Jagiellonian University Medical College in Krakow.

Aim: For the first time the AISN PTK report is based on the new electronic database implemented in Poland on January $1^{\text {st }}, 2014$.

Material and methods: In 2014, there were 155 invasive cardiology centers registered in the ORPKI database (an increase by 1 center in comparison to 2013) and $92 \%$ of them had $24 / 7$ percutaneous (PCI) duty. For the first time the number of catheterization laboratories (cath labs) in Poland remained stable, and even though there was an increase by 1 in absolute numbers, 2 cath labs ceased to admit patients in 2014. This means that the number of active cath labs per 1 million inhabitants is similar to last year and equals 4.

Results: In comparison to 2013, there was a significant increase in the total number of coronary angiographies. There were 226713 angiographies in 2014. The total number of PCI procedures was 126 241, which is 5.1\% more than in 2013.

Conclusions: There was a significant increase in the overall number of coronary angiographies and PCls in Poland in 2014. The use of attributes of modern interventional cardiology such as drug-eluting stents and bioabsorbable vascular stents is growing as well as more frequent choice of a radial access site by PCl operators even in ST-elevation myocardial infarction patients. One should also note a significant rise in the use of additional imaging or diagnostic tools such as fractional flow reserve, intravascular ultrasound and optical coherent tomography.
\end{abstract}

Key words: registry, acute coronary syndromes, coronary angiography.

The Board of the Association of Cardiovascular Interventions of the Polish Cardiac Society (AISN PTK) publishes annual data from the National PCI Registry (ORPKI) operated by the Jagiellonian University Medical College in Krakow. For the first time the AISN PTK report is based on the new electronic database implemented in Poland on January $1^{\text {st }}, 2014$ and verified independently by data submitted to AISN PTK by individual centers.
In 2014, there were 155 invasive cardiology centers registered in the ORPKI database (an increase by 1 center in comparison to 2013) and $92 \%$ of them had $24 / 7$ percutaneous coronary intervention $(\mathrm{PCl})$ duty. For the first time the number of catheterization laboratories (cath labs) in Poland remained stable, and even though there was an increase by 1 in absolute numbers, 2 cath labs ceased to admit patients in 2014. This means that

Corresponding author:

Zbigniew Siudak MD, PhD, Department of Interventional Cardiology, Jagiellonian University Medical College, 17 Kopernika St, $31-501$ Krakow, Poland, phone: +48 1242471 81, e-mail: zbigniew.siudak@uj.edu.pl

Received: 14.05.2015, accepted: 15.05.2015. 
the number of active cath labs per 1 million inhabitants is similar to last year and equals 4 . There are 571 certified independent $\mathrm{PCl}$ operators in Poland in 2015 with $100 \%$ of them having any board certification and $74 \%$ in cardiology. Center accreditation issued by AISN PTK was awarded to 104 cath labs.

In comparison to 2013, there was a significant increase in the total number of coronary angiographies. There were 226713 angiographies in 2014 (an increase by $4.8 \%$ - Figure 1. Patients' baseline characteristics and prevalence of risk factors are presented in Table I.

The reason for performing coronary angiography in Polish patients in 2014 is presented in Table II. In more than half of the cases it was the diagnosis of an acute coronary syndrome.

A radial approach is used in as many as $66 \%$ of all cases of coronary angiography, which represents a $13 \%$ rise since 2013 . The right radial artery is predominant when radial access is chosen (87\%). Radial access site choice according to baseline diagnosis is presented in Figure 2.

Common complications of coronary angiography were rare in 2014 and occurred predominantly in myocardial infarction cases. Detailed description and odds of occurrence are presented in Table III.

The total number of $\mathrm{PCl}$ procedures was 126 241, which is $5.1 \%$ more than in 2013 . The change in overall number of PCls in the last 10 years is presented in Figure 3.

Percutaneous coronary interventions performed in acute coronary syndromes accounted for $62 \%$ of all PCl cases in 2014 - details are presented in Table IV. There were 26678 primary PCls in a ST-elevation myocardial infarction (STEMI) setting, which is similar to 2013 and translates into 692 primary PCls per 1 million inhabitants in STEMI in Poland in 2014, which puts us in $4^{\text {th }}$ place in Europe according to the recent paper from the Europe-

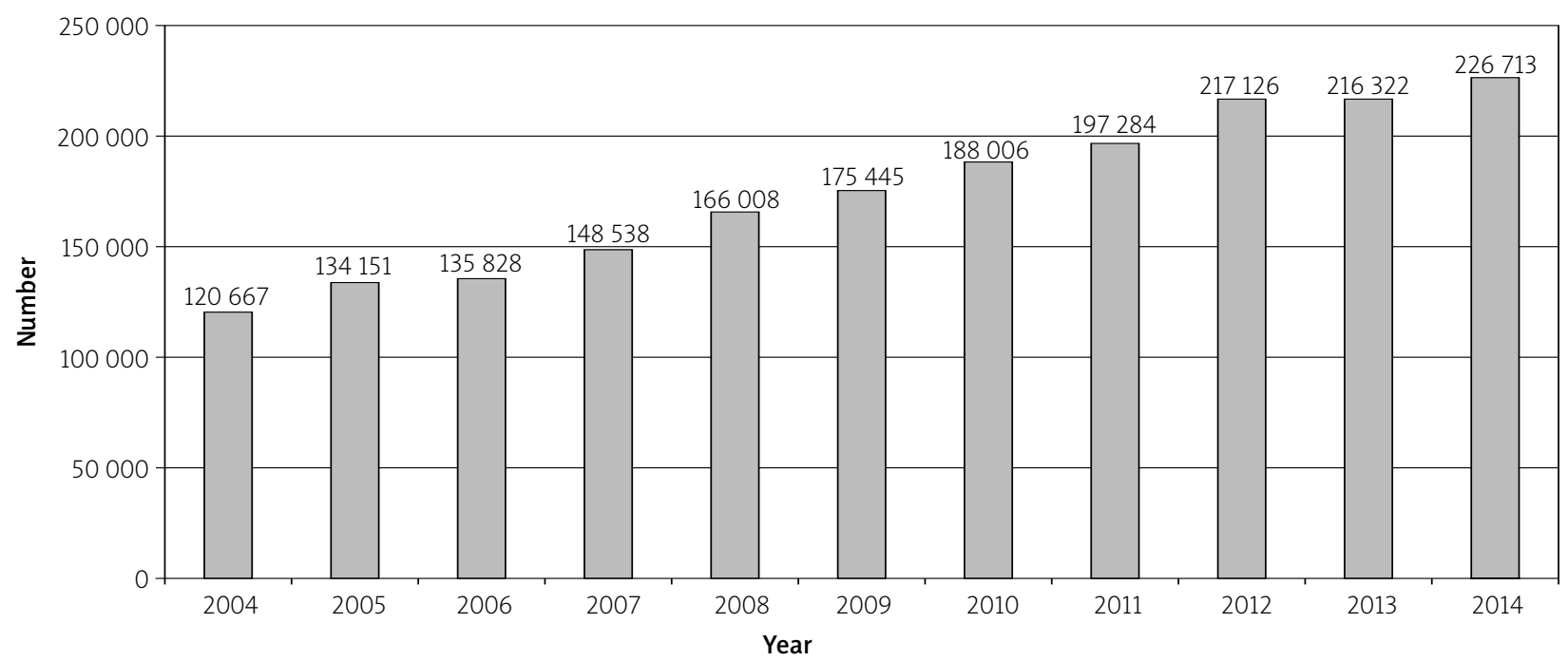

Figure 1 . The number of coronary angiography procedures in Poland in the years 2004-2014

Table I. Demographics and prevalence of risk factors in patients who underwent coronary angiography in 2014

\begin{tabular}{lc} 
Name & Percent or mean \\
\hline Age & $66.2 \pm 10.9$ \\
\hline Gender, female & 38 \\
\hline Prior stroke & 3.2 \\
\hline Prior myocardial infarction & 22.7 \\
\hline Prior PCl & 25 \\
\hline Prior CABG & 5.8 \\
\hline Smoking & 17.5 \\
\hline Arterial hypertension & 71.5 \\
\hline Chronic kidney disease & 5.2
\end{tabular}

$P C l$ - Percutaneous coronary intervention, $C A B G$ - coronary artery bypass graft.
Table II. Baseline diagnosis in patients who underwent coronary angiography

\begin{tabular}{lc} 
Diagnosis & Percent \\
\hline STEMI & 12.2 \\
\hline NSTEMI & 13.4 \\
\hline Unstable angina & 29.8 \\
\hline Stable CAD & 39.9 \\
\hline Other & 4.7
\end{tabular}

STEMI - ST-elevation myocardial infarction, NSTEMI - non-ST-elevation myocardial infarction, CAD - coronary artery disease. 


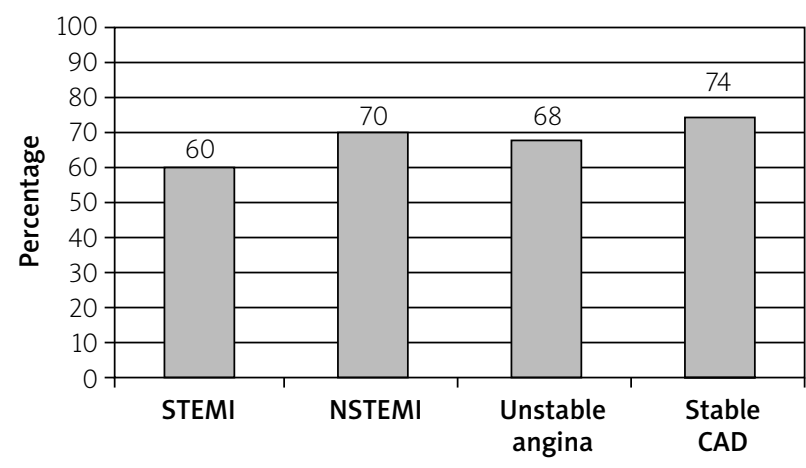

Figure 2. Radial approach according to diagnosis
Table III. Periprocedural complications - coronary angiography

\begin{tabular}{lcc} 
Name & Percent & Occurrence \\
\hline Death: & 0.047 & $1 / 2130$ \\
\hline In STEMI/NSTEMI & 0.12 & $1 / 850$ \\
\hline In stable CAD & 0.04 & $1 / 2378$ \\
\hline Stroke & 0.015 & $1 / 6528$ \\
\hline Major bleeding from access site & 0.051 & $1 / 1965$ \\
\hline Cardiac arrest & 0.232 & $1 / 431$ \\
\hline Anaphylaxis & 0.045 & $1 / 2224$
\end{tabular}

STEMI - ST-elevation myocardial infarction, NSTEMI - non-ST-elevation myocardial infarction, CAD - coronary artery disease.

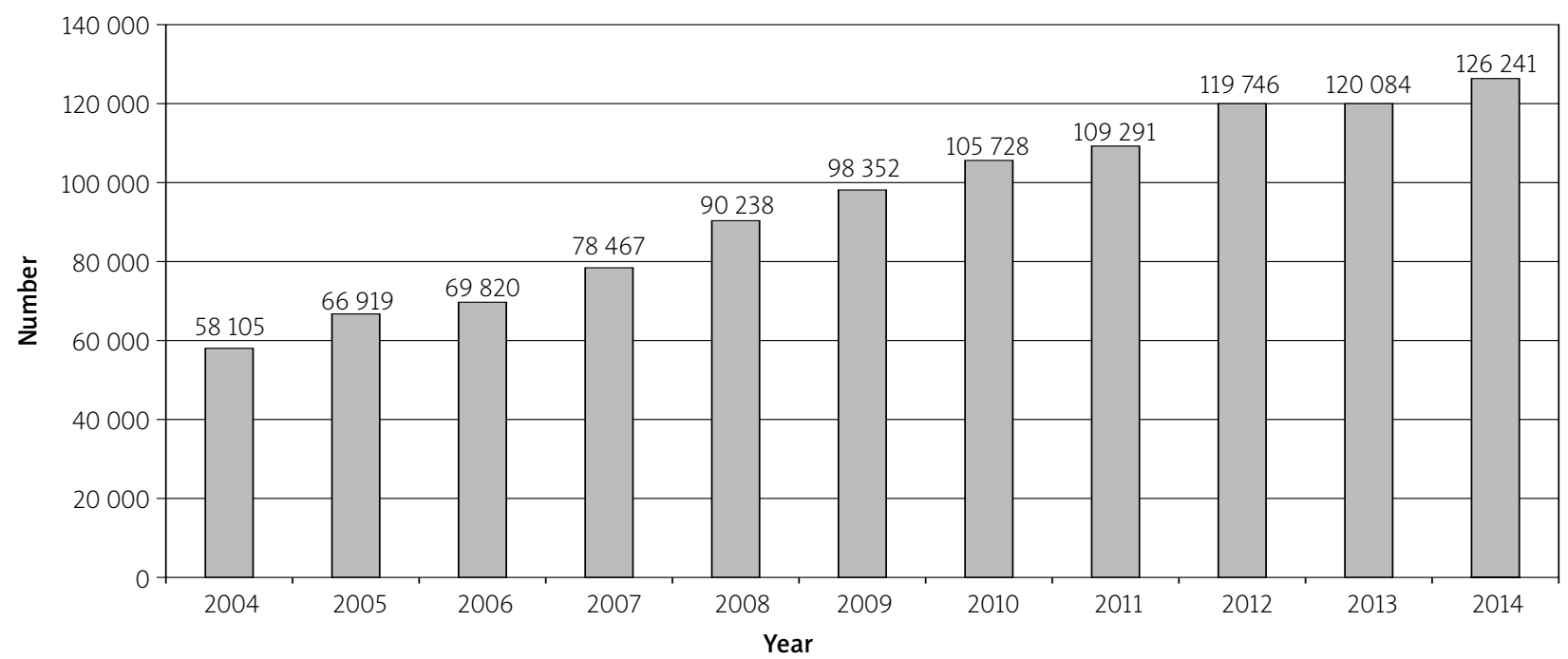

Figure 3. The number of coronary angioplasty procedures in Poland in the years 2004-2014

Table IV. Percutaneous coronary intervention in acute coronary syndrome

\begin{tabular}{lc} 
Diagnosis & Percent \\
\hline STEMI & 33 \\
\hline NSTEMI & 28 \\
\hline UA & 39 \\
\hline All & 100
\end{tabular}

STEMI - ST-elevation myocardial infarction, NSTEMI - non-ST-elevation myo cardial infarction, UA - unstable angina.

an Heart Journal on implementation of the Stent For Life program and is lower than in 2013.

Drug-eluting stents (DES) during $\mathrm{PCl}$ were used in $83.5 \%$ of cases which is $16.5 \%$ more than in 2013 and is steadily rising since 2008 . Bioabsorbable vascular stents (BVS) were implanted in $1.5 \%$ of patients (both in acute

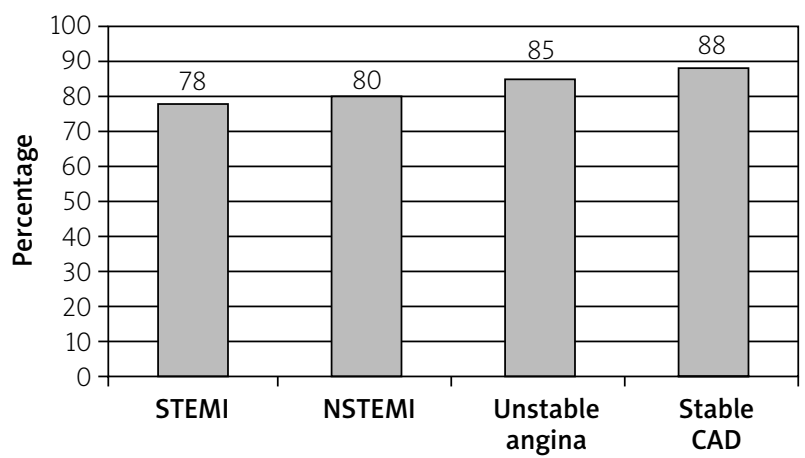

Figure 4. Drug-eluting stents stents by diagnosis in 2014

coronary syndrome (ACS) and in stable angina). In patients with stable angina the prevalence of DES stents was as high as $88 \%$ - see details in Figure 4 . On the other hand, there was a $34 \%$ decrease in the use of GP IIb/IIla blockers in the overall population. In patients with STEMI GP IIb/IIla were used (elective and bail-out) in only $1 / 3$ 


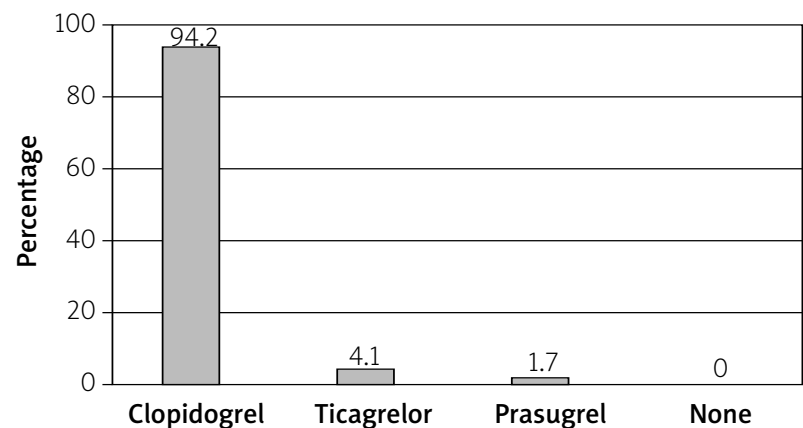

Figure 5. Antiplatelet agents in ST-elevation myocardial infarction

of cases. Aspiration thrombectomy was rare $(17.8 \%)$ in STEMI cases.

The use of modern antiplatelet agents advised by the ESC guidelines such as ticagrelor and prasugrel was very low in 2014 in Poland and less than 6\% in STEMI and non-ST-elevation myocardial infarction (NSTEMI) populations - for details see Figures 5 and 6 .

Percutaneous coronary intervention complications during $\mathrm{PCl}$ were highest (death) in a STEMI setting and are presented in Table $\mathrm{V}$.

A noticeable increase in the rate of modern diagnostic procedures other than coronary angiography (e.g. intravascular ultrasound - IVUS, fractional flow reserve FFR, optical coherent tomography - OCT) was observed in 2014. There were 4019 FFR procedures (increase by 85\%), 1884 IVUS examinations (increase by $30 \%$ ) and 371 OCTs (increase by $89 \%$ ).

Percutaneous extracardiac procedures were also gathered in the new ORPKI database. In 2014 transcatheter aortic valve implantation (TAVI) was performed in 451 patients, percutaneous left atrial appendage closure in 137 cases and therapeutic hypothermia after sudden

Table V. Periprocedural complications - percutaneous coronary intervention

\begin{tabular}{lcc} 
Parameter & Percent & Occurrence \\
\hline Death & 0.49 & $1 / 204$ \\
\hline STEMI & 1.61 & $1 / 62$ \\
\hline NSTEMI & 0.52 & $1 / 192$ \\
\hline Stable CAD & 0.12 & $1 / 843$ \\
\hline Myocardial infarction & 0.12 & $1 / 812$ \\
\hline Major bleeding from access site & 0.13 & $1 / 783$ \\
\hline Cardiac arrest & 0.43 & $1 / 234$ \\
\hline Anaphylaxis & 0.13 & $1 / 812$ \\
\hline Artery perforation & 0.17 & $1 / 598$ \\
\hline No reflow & 0.61 & $1 / 181$
\end{tabular}

STEMI - ST-elevation myocardial infarction, NSTEMI - non-ST-elevation myocardial infarction, CAD - coronary artery disease.

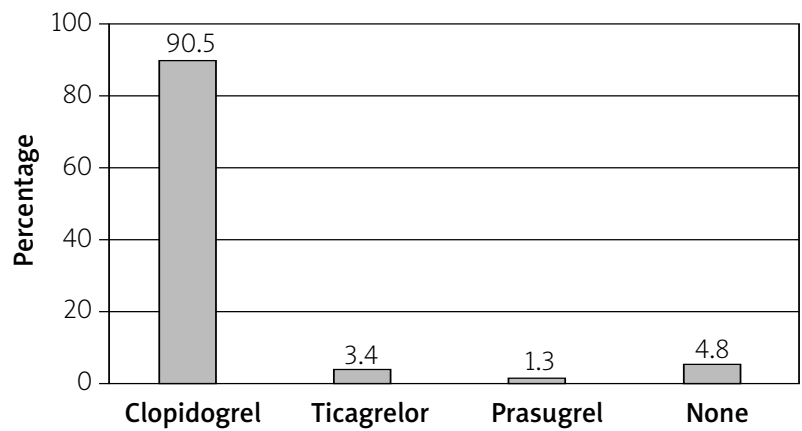

Figure 6. Antiplatelet agents in non-ST-elevation myocardial infarction

cardiac arrest in 115 . The numbers of selected non-coronary procedures in 2014 are presented in Table VI.

In summary, there was a significant increase in the overall number of coronary angiographies and $\mathrm{PCls}$ in Poland in 2014. The number of active cath labs in Poland remains stable for the $2^{\text {nd }}$ consecutive year though, which might relate to the fact that the country is now well saturated with interventional cardiology centers. On

Table VI. The number of selected non-coronary procedures in 2014, performed in cardiac centers for adults in Poland

\begin{tabular}{lc} 
Selected procedures & Number, $n$ \\
\hline PTA below the knee & 481 \\
\hline PTA above the knee & 1599 \\
\hline Carotid artery stenting & 662 \\
\hline Vertebral artery stenting & 50 \\
\hline Renal artery stenting & 66 \\
\hline Subclavian artery stenting & 150 \\
\hline Mitral valvuloplasty & 57 \\
\hline Pulmonary valvuloplasty & 50 \\
\hline BAV & 203 \\
\hline PFO closure & 339 \\
\hline ASD closure & 333 \\
\hline VSD closure & 10 \\
\hline PDA closure & 76 \\
\hline LAA closure - percutaneous & 137 \\
\hline TAVI & 451 \\
\hline Therapeutic hypothermia & 115 \\
\hline Renal denervation & 39 \\
\hline Myocardial biopsy & 740 \\
\hline & \\
\hline
\end{tabular}

ASD - Atrial septal defect, BAV - baloon aortic valvuloplasty, LAA - left atrial appendage, PDA - patent ductus arteriosus, PFO - patent foramen ovale, PTA percutaneous transluminal angioplasty, VSD - ventricular septal defect. 
the other hand, the use of attributes of modern interventional cardiology such as DES and BVS stents is growing as well as more frequent choice of a radial access site by $\mathrm{PCl}$ operators even in STEMI patients. One should also note a significant rise in the use of additional imaging or diagnostic tools such as FFR, IVUS and OCTs in Poland in 2014.

\section{Conflict of interest}

The authors declare no conflict of interest.

The manuscript is also available in Polish in "Kardiologia Polska" based on the mutual agreement of Editors and Publishers. 